April 10th, 1901, that is, say, 12 weeks. This patient recovered.

Summarising these four cases, two of which terminated fatally, the patients received weekly quantities of mercury which work out as follows :-Case 1: 36 grains over a period of 30 weeks $=1 \frac{1}{5}$ grains a week for 30 weeks. Case 2: 32 grains over a period of 18 weeks $=1 \frac{7}{9}$ grains a week for 18 weeks. Case 3: 34 grains over a period of 32 weeks $=11_{16}^{1}$ grains a week for 32 weeks. Case $4: 18$ grains over a period of, say, 12 weeks $=1 \frac{1}{2}$ grains a week for 12 weeks.

Let us compare these figures with those based on Major French's six weekly injections of one grain each followed by from two to three months rest. Here we have, allowing two months rest, six grains of $\mathrm{Hg}$ over a period of 14 weeks $=\frac{3}{7}$ grain a week; or allowing three months rest, six grains of $\mathrm{Hg}$ over a period of 18 weeks $=\frac{1}{3}$ grain a week. Comparing the latter with the period of 18 weeks of Case 2 , during which the patient received 32 grains in all, or $1 \frac{7}{9}$ grains a week, nearly two grains, the discrepancy is great.

Taking two of the periods recommended by Major French, we have, with two months rest, 12 grains of $\mathrm{Hg}$ given over a period of 28 weeks $=3$ grain a week; and allowing three months rest we have 12 grains of $\mathrm{Hg}$ over a period of 36 weeks $=\frac{1}{3}$ grain a week. Compare this with Case 1 , in which the patient received 36 grains in 30 weeks, or $1 \frac{1}{5}$ grains a week; or with Case 3 , in which 34 grains were injected over a period of 32 weeks, or $1 \frac{1}{15}$ grains a week ; or, again, with Case 4, in which 18 grains were given in 12 weeks, or $1 \frac{1}{2}$ grains a week. If it be objected that the periods should be reckoned from the first injection to the twelfth, and that is making a concession of time to Major French, we have with two months rest 12 grains of $\mathrm{Hg}$ distributed over a period of 20 weeks $=\frac{3}{5}$ grain a week; or, with three months interval, 12 grains over a period of 24 weeks $=\frac{1}{2}$ grain a week.

On Major French's own showing the amount injected should be somewhere about half a grain a week. It is a pity that Major French in his obvious desire to crush me with his critical rejoinder did not examine these four cases a little more critically before quoting them. I repeat I did not include them in my American paper, although these cases would have supported $\mathrm{mg}$ contention that in fatal cases and in bad cases of stomatitis the doses of mercury had been too large. Indeed, when I was preparing my paper I decided to leave out all references to cases occurring in British army practice, and I limited myself to the examination of cases recorded in civil practice, so that Major French's contradiction of my statement that intramuscular injections of insoluble mercurial preparations are not employed to any extent in England and the United States does not amount to anything. Incidentally in my paper I did refer to the fact that the method was used in the British army, thanks to the efforts of Colonel Lambkin, whose pioneer work deserves every recognition. Perhaps Major French overlooked this when he read my paper, but I think that before contradicting me so categorically he might have done me the honour of making sure of his ground.

I do not mind meeting Major French half way by examining the four cases reported by Surgeon-General Fawcett and which occurred in Egypt, but I refuse to follow him to India and to go east of Suez. Syphilis among soldiers in India needs to be taken very much on its merits. East is East and West is West,

"And the wildest dreams of Kew are the facts of Khatmandhu, And the crimes of Clapham chaste in Martaban."

Major French misquotes me when he says that I state: "I have only employed the intramuscular injections in my private practice. No ill-effects ensue after 10-12 consecutive weekly injections of doses varying from 1-10 certigrammes." What I really did say is this: "As far as my own work goes, I may say I have only employed the intramuscular injections of insoluble preparations in my private practice. I have never seen any complications arise. My results have been very satisfactory and I consider the method a most valuable one, especially when any serious syphilitic com plication threatens. My experience of the early abortive intense (italics are in my paper) treatment has been from the nature of private practice very limited, and I have not felt justified in applying it to its full extent. But where full control of the patient could be obtained I have found no ill-effects ensue after 10 or 12 consecutive weekly injections of doses varying from 7 to 10 centigrammes."
I would insist here that my reference to the use of 10 to 12 injections relates to the so-called early intense abortive treatment of syphilis, and not to ordinary treatment. Major French's mangled quotation of my printed words is a misrepresentation of my views and practice. To take two sentences totally unrelated to each other and quote them in direct consecutive order - that is, without any indication that there were other sentences between them - is an unwarrantable procedure. The matter is made worse by the remarks of Major French which immediately follow his misquotation of what I said and wrote. I insist on this, as such a way of putting it must necessarily create prejudice.

As to other points, I inay tell Major French that in his references to severe mercurial dermatitis he is sending coals to Newcastle as far as I am concerned.

His remarks as to Professor Fournier's attitude in the matter of insoluble preparations are not up to date. I know Professor Fournier and his son, Dr. Edmond Fournier, personally. They both employ huile grise in intramuscular injection. Indeed, it is not so long ago that a patient was directed to me with a request from Professor Fournier himself that I should continue injections of huile grise in the case. I have habitually used Dr. Edmond Fournier's syringe specially devised for huile grise, to which I alluded in my paper.

With regard to the two fatal cases following inunction treatment, one of which I took from the practice of Dr. Mayer of Aix-la-Chapelle, ${ }^{2}$ the fact remains that the inunctions led to a fatal issue. These are not the only two cases that might be brought forward against the inunction treatment, but I was careful to add in my paper that "that would surely be no reason for damning a method that is valuable."

In my American paper I dealt fairly and squarely with the whole matter, as far as the limits of time would allow me. I stated distinctly that in the treatment of syphilis I was eclectic as to the method to be employed; all methods had their place. Moreover, I insisted on the importance of not treating cases by intramuscular injections of insoluble preparations in a routine way, adding that in certain circumstances which I enumerated, insoluble preparations were absolutely contra-indicated. I did not advocate their use for all and sundry, but put in a plea for a better recognition of a valuable addition to our armamentarium in fighting syphilis. I looked at all sides of the question and did $\mathrm{my}$ best. I may say that at Atlantic City, although many among my audience were not favourably inclined to insoluble preparations of mercury, they quite appreciated the fact that I had dealt with the method frankly and fairly, and that I had pointed out its dangers as well as its advantages.

I am, Sir, yours faithfully,

Harley-street, W., Sept. 27th, 1909. George Perner, M.D.

\section{IS SNOW-WATER UNWHOLESOME?}

\section{To the Editor of THE LANCET.}

SIR,--If I may add a few words to the discussion upon the influence of snow-water that has been taking place in your columns recently I should like to draw attention to some interesting though almost forgotten observations made amongst the Cree Indians in North-West Canada in the year 1819-20, by John Richardson, M.D., F.R.S., F.L.S., who accompanied Captain John Franklin, R.N., F.R.S., upon the first and second of his voyages to the shores of the Polar seas in search of the North-West passage.

Dr. Richardson's observations in his own words are as follows: "Bronchocele, or goitre, is a common disorder at Edmonton. I examined several of the individuals afflicted with it, and endeavoured to obtain every information on the subject from the most authentic sources. The following facts may be depended upon. The disorder attacks those only who drink the water of the river. It is indeed in its worst state confined almost entirely to the halfbred women and children, who reside constantly at the fort, and make use of river water, drawn in the winter through a hole cut in the ice. The men, being often from home on journeys through the plain, when their drink is melted snow, are less affected; and, if any of them exhibit during the winter some incipient symptoms of the complaint the annual summer voyage to the sea-coast generally effects a cure. The natives who confine themselves to snow water in the 
winter, and drink of the small rivulets which flow through the plains in the summer, are exempt from the attacks of this disease. These facts are curious, inasmuch as they militate against the generally received opinion that the disease is caused by drinking snow-water-an opinion which seems to have originated from bronchocele being endemial to subalpine districts. The Saskatchawan, at Edmonton, is clear in the winter, and also in the summer, except during the May and July floods. The distance from the Rocky Mountains (which I suppose to be of primitive formation) is upwards of one hundred and thirty miles. The neighbouring plains are alluvial, the soil is calcareous and contains numerous travelled fragments of limestone. At a considerable distance below Edmonton, the river, continuing its course through the plains, becomes turbid, and acquires a white colour. In this state it is drunk by the inmates of Carlton House, where the disease is known only by name. It is said that the inhabitants of Rocky Monntain House, sixty miles nearer the source of the river, are more severely affected than those at Edmonton. The same disease occurs near the source of the Elk and Peace Rivers; but, in those parts of the country which are distant from the Rocky Mountain Chain, it is unknown, although melted snow forms the only drink of the natives for nine months of the year. A residence of a single year at Edmonton is sufficient to render a family bronchocelous. Many of the goitres acquire great size. Burnt sponge has been tried and found to remove the disease, but an exposure to the same cause immediately reproduces it. A great proportion of the children of women who have goitres are born idiots, with large heads, and the other distinguishing marks of cretins. I could not learn whether it was necessary that both parents should have goitres, to produce cretin children; indeed, the want of chastity in the half-bred women would be a bar to the deduction of any inference on this head."

I am, Sir, yours faithfully,

Wimpole-street, W., Oct. 5th, 1909. HERBERT FRENCH.

\section{DOMICILIARY MEDICAL TREATMENT UNDER THE POOR-LAW.}

\section{To the Editor of THE LANCET.}

SIR,-With your permission I should like to say a few words about the "two most cogent reasons" that Dr. $H$. Beckett-Overy refers to in his letter published in your issue of Oct. 2nd, p. 1026, which he objects to being defined as " mere negations." The first reason I specifically dealt with, and pointed out the impossibility of recovering charges by any legal process from "poor persons," where the first requisite under any enactment would be to prove ability to pay. I instanced the failure in the past to recover anything beyond the most trivial proportion of the relief granted "on loan" under the present system, the principle of which is indistinguishable from that recommended by both the Majority and Minority Commissioners. The restatement of these recommendations without any reference to my criticism Dr. Beckett-Overy does not consider a "mere negation." In his last letter he states that $£ 300,000$ have been recovered in various ways by all the authorities having any connexion with the Poor-law. That this is an attempt to meet my criticism I am quite ready to admit, but I demur to its cogency. For aught I know, the $£ 300,000$ recovered may be as trifling a proportion of the amount expended as the "relief on loan" recoveries. The inclusion of lunacy institutions nullifies any value it might have as a comparison, as it is notorious that the great bulk of the middle classes of the country make use of these instead of private institutions, with the full knowledge that they must pay for their relatives. From many of these no doubt the cost could be readily recovered. With regard to the second reason-viz., the effect that inability to choose their doctor would have in preventing abuse of gratuitous medical attendance-nothing was said in Dr. Beckett-Overy's first letter, unless it is to be inferred from the general approval of the views of the Minority Commissioners. I admit I called it a mere negation, and do not see why I should alter my opinion. The suggestion now made that this would be a sufficient check is, in my opinion, a very weak argument. No doubt, among the large class of poor persons to whom I refer, most would prefer to choose their doctor, but I have no hesitation in saying from the experience of a lifetime among that class that the choice would be largely swayed by the cost to themselves. Where State-guaranteed medical attendance could be had for nothing it would show very unusual belief in a particular doctor for the patient to prefer the latter if he had to pay him. It is a fact only too cognisant to practitioners among the poor that a difference of sixpence in the fee will detach a patient from a doctor who has attended him for years and send him to an unknown new-comer.

London, Oct. 2nd, 1909. I am, Sir, yours faithfully,

\section{DISPENSERS IN PUBLIC INSTITUTIONS FOR THE SICK.}

\section{To the Editor of THE LANCET.}

SIR,-I am instructed to forward you a copy of a letter dealing with the question of dispensing in public institutions which has been drawn up by the National Union of Assistant Pharmacists and which is to be sent to those concerned as occasion arises.-I am, Sir, yours faithfully,

EDw. S. FrancIs, M.P.S.,

$$
\text { Honorary General Secretary. }
$$

$$
\text { [COPY.] }
$$

The National Union of Assistant Pharmacists has considered the question of dispensing in public institutions and has decided that it is in the public interest that the attention of public bodies and others having the appointing of a dispenser should be drawn to the following facts and for which we respectiully ask your consideration :-

(1) The Pharmacy Act restricts the open sale of poisons to duly (1) The Pharmacy Act restricts the open sale of poisons to duly
qualified "chemists and druggists" who have been trained and examined by the Pharmaceutical Society, so that they are fully informed as to the nature and properties of poisons. We submit that informed as to the nature and properties of poisons. We submit that
it is a necessity for the public safety that poisons which are dispensed it is a necessity for the public safety that poisons which are dispensed
in large quantities in public institutions should be under the controi in large quantities in public institutions should be under the controi registered "chemist and druggist" (i.e., a pharmacist) as dispenser.

registered "chemist and druggist" (i.e., a pharmacist) as dispenser. (2) The remuneration offered for the services of a dispenser is frequently such as to admit only of securing persons holding certificates other than the diploma of the Pharmacentical Society (the recognised
standard of efficiency), and as the training for the diploma is long and expensive, we consider $£ 130$ per annum to be the minimum salary, irresvective of sex, for the professional and responsible services of a dispenser.

We ask your support in securing to us these rightful conditions in recognition of the fact that it is necessary for us to undergo special training in the interests of the safety and service of the community.

Signed on behalf of the National Union of Assistant Pharmacists.

\section{THE BENHAM TOP.}

To the Editor of THE LANGET.

Sir,-In Dr. F. W. Edridge-Green's valuable paper on the Theory of Vision, published in THE LANCET of Oct. 2nd, brief reference is made to the Benham top, and an explana. tion is offered to the effect that the lines appear red because this is the contrast colour to the green which is seen as the after-image of the black half of the disc. Assuming that black does give an after-image of green to normal sight in a bright light, Dr. Edridge-Green seems to overlook the fact that the lines being themselves black should have an after-image of green. In a paper by Mr. F. Peake Sexton published in the 1lluminating Engineer last May what has seemed to me a complete explanation of the colour effects in the Benham top has been offered. His theory is based on the fact that the duration of the impression of light on the retina varies for different wave lengths, and he shows how this circumstance completely accounts for all the colour effects of the top and their reversal on reversing the direction of rotation. It is a question of the rate both of growth and decay of colour sensation.

$$
\begin{gathered}
\text { I am, Sir, yours faithfully, } \\
\text { Colchester, Oct. 1st, 1003. } \quad \text { CHARLES E. BENHAMr. }
\end{gathered}
$$

\section{CHRISTIAN SCIENCE IN RELATION TO THE WORKMEN'S COMPENSATION ACT.}

\section{To the Editor of THE LANCET.}

SIR, - What is the doctor's duty in the following case? A very intelligent artisan, whom $I$ had been treating some two years ago for syphilis, came to me recently complaining of giddiness, reeling, and other cerebral symptoms which I concluded were caused by a syphilitic tumour. Having plainly expressed my opinion, I told him that it was probable he would be cured if he continued treatment long enough. "I came to you," quoth he, "for diagnosis, not for treatment. 